\title{
Proof
}

\section{(Saving the City)}

\author{
ELIJAH HUGE \\ Wesleyan University
}

In 1752, the year Benjamin Franklin is credited with the invention of the lightning rod, he also established the first American fire insurance company. The coincidence of these innovations prefigures the parallel development and interwoven relationships between invention, building insurance, and legislation that underlie the production of architecture today. Industrialization brought new threats to the city (e.g. electricity, speed, explosives) while also dramatically increasing the scale of historical perils (e.g. flood, fire, theft). In turn, these threats gave rise to a field of new products, accessory to conventional building. In their early forms, the automatic sprinkler, exterior fire escape, panic bar, emergency light, and theft alarm were, like Franklin's lightning rod, ready for production and deployment on a large scale, without definitive spatial identity, and suitable for use in new or existing construction. Negotiating the thresholds between the developing infrastructures of the city and its private spaces (as insured and legally defined), these devices may be understood collectively as a crumple zone intended not to prevent architectural emergency but to absorb, limit, and contain its effects.

\section{INTRODUCTION}

Before a new device finds acceptance in the market, its reception is frequently lubricated with broad claims and circumferential threats that are, in turn, supported, when available, by performance-based evidence. The calamities used for testing are typically simulated or mythological, with architectural models a favored testing grounds. While architecture often seeks to over-come its own technological limitations, there are usually dangers associated with doing so that are either already well-documented or waiting to be discovered. Lightning offers both.

"The record of damage to churches, whose elevated steeples attract lightning, is voluminous...Perhaps the most famous of these structures is the Campanile of St. Mark in Venice ...It was severely damaged by a stroke in 1388, at which time it was a wooden structure. In 1417 it was set on fire by lightning and destroyed. In 1489 it was again reduced to ashes. In 1548, 1565 , and 1653 it was damaged more or less severely, and in 1745 a stroke of lightning practically ruined the whole tower. Repairs cost 8,000 ducats . . . but in 1761 and 1762, it was again severely damaged. In 1766 a Franklin rod was installed on it and no further trouble from lightning has occurred since (figure 1)."1

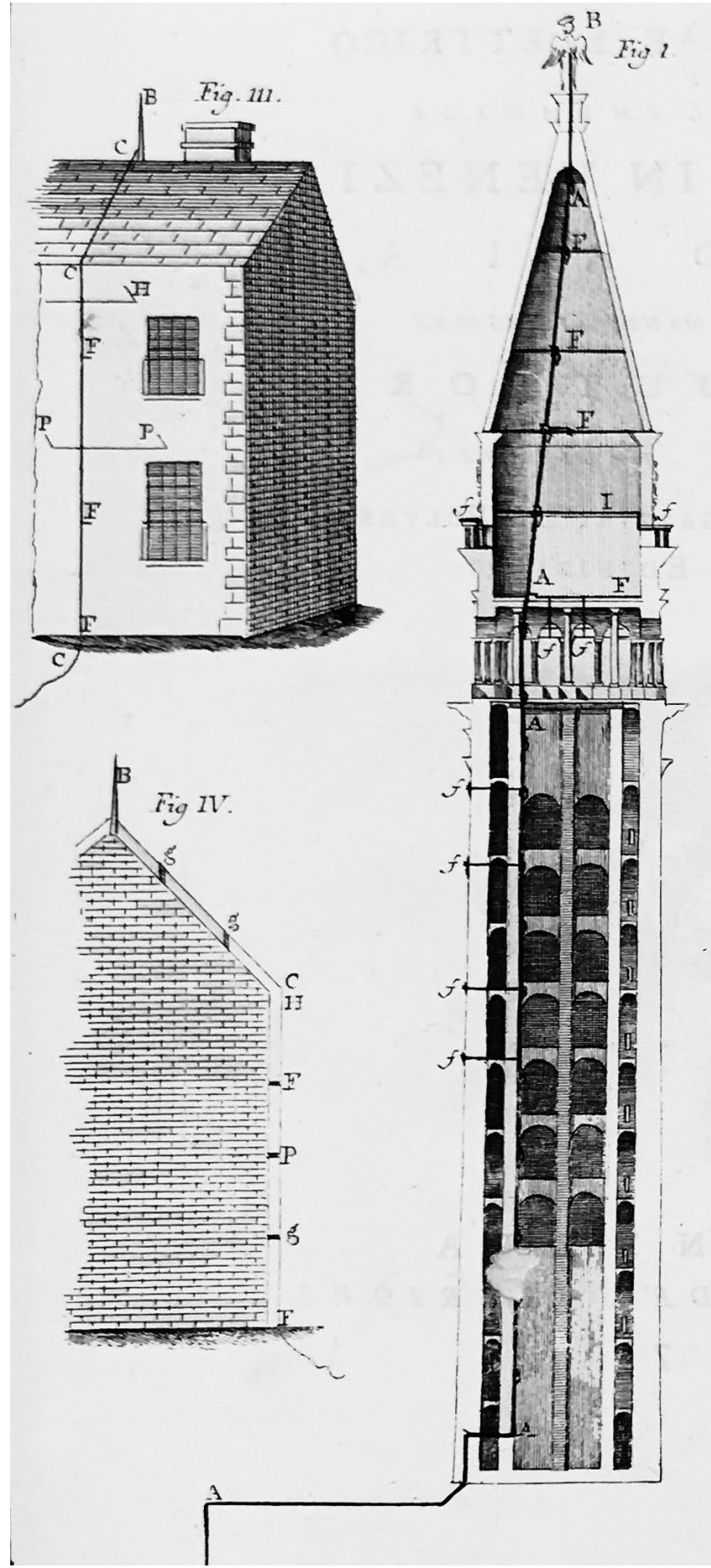

Figure 1: The Franklin based lighting protection system designed by Giuseppe Toaldo for the San Marco Campanile in Venice. Published in GiuseppeToaldo, "Del conduttore elettrico posto nel campanile," Padua, 1776 . 
There are multiple mythologies surrounding Franklin's recognition of lightning as a form of electricity, but at their core is an act of speculation and an architect's willingness to create analogies across scales. Franklin was introduced to electricity through the demonstrations of Archibald Spencer, while visiting Boston in the mid 1740s, after which he began to treat his own house as a kind of laboratory. The hypothesis that lightning is a form of electricity was not uniquely Franklin's, but is first recorded in a letter Franklin sent to Peter Collinson (a member of the Royal Society in London who had supplied Franklin with electrical apparatus) in 1749. However, the corresponding proof would be architectural in both formulation and execution.

\section{THUNDER HOUSE}

When Ebenezer Kinnersly, a close friend and collaborator of Franklin's, embarked on his public electrical lectures during the late 1740 s and early 1750 s, his most dazzling performance piece was the thunder house, a small model house or church, usually made of wood, which he used for demonstrating Franklin's latest invention, the lightning rod. "The thunder house visualized Franklin's assertion that lightning and electricity were related natural phenomena. Further still, the performance suggested that by using conductors - that is, lightning rods - humans could harness electricity's destructive potential (figure 2 )."

The thunder house is an "electrical machine," and as such can be placed alongside a wide range of 18th century electrical machines that were used in experiments and demonstrations for both research and entertainment (the line between these being almost nonexistent at the time). However, unlike other electrical machines, it is also quite clearly an architectural model designed to evoke an architectural condition, stable and familiar. It is a house model, but not the model of any particular house. It represents "house" as a condition, an abstraction, archetypal, recognizable only through basic signifiers: the profile of a roof, a chimney, windows.

The success of the model is both in its dramatic representation of architectural failure and its promise of safety, provided not by the security of architectural enclosure, but by the proper installation of a device for securing against destruction from a specific threat. The sturdy and precious materials - mahogany and brass - enhance the effect. A typology emerges and variations are developed: a "Thunder Façade," a "Thunder obelisk," a model of a room in which the gold-leafed wallpaper and gilt picture frames, on being electrified, transfer current to the room's paper-doll occupants, knocking them over or setting them aflame, as demonstrated in an "Electrostatic Lightning House" on display in the Oxford Museum of the History of Science, which is identified as being manufactured by W. \& S. Jones, London circa 1830, and based on actual events.



Figure 2: 18th Century "Thunder House" Model.

The model is a tool for both simulation and demonstration testing and evidencing (figure 3 ). It is a performer with two successive roles. A simple adjustment renders the conductor discontinuous and transforms the model from a stable system to dangerous pile. This is accomplished with a moveable part. It is not unlike a door, a window, a hinge between safety and calamity. The space between the two is a thin line of brass, cutting across the façade of the house and either completing the circuit or rendering it discontinuous.

Much of the science of the 18th century developed by analogy, and the thunder house is no exception - it is a kind of tabletop primitive hut. This blurring of scales could move in both directions. The house model as both a representational device and a portal - threatening the idea of house a particularly effective strategy with public audiences. The wires, needles, balls at the scale of the tabletop experiment could be translated to the scale of architecture.

The effectiveness of the lightning rod could be shown in the comfort of the parlor - the model would be a vehicle not for communicating construction methods or design intent, but to demonstrate architecture's vulnerability, to show that the presence of a simple device could be the difference between stability and catastrophe. Destruction could arrive at any moment. Interestingly, the Thunder House was being used to demonstrate that metal conductors could be used to protect buildings from lightning before it was established that lightning was, in fact, a form of electricity. 


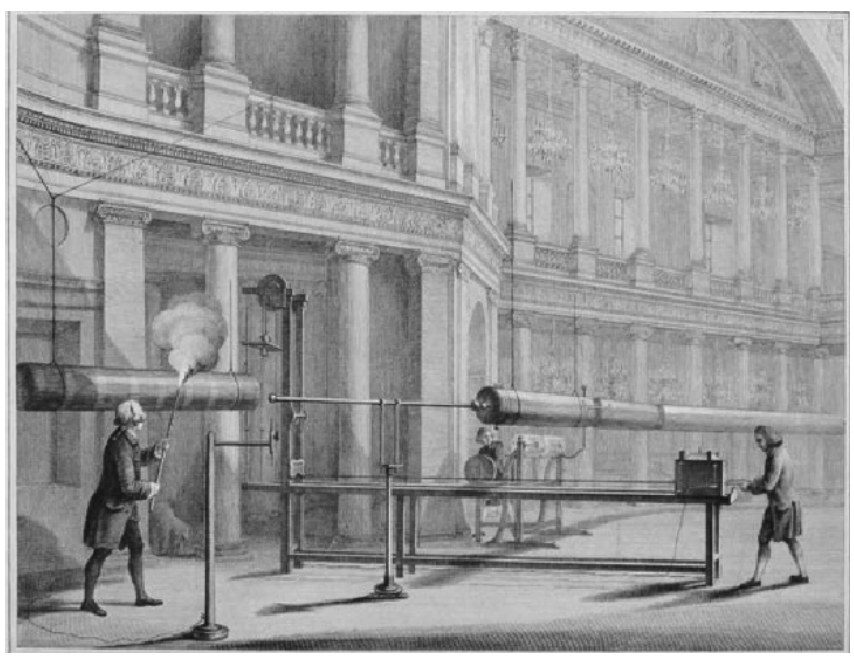

Figure 3: The architectural model as instrument for performance and scientific experiment, "A View of the Apparatus and part of the Great Cylinder in the Pantheon," M.A. Rooker, Engraved by J. Basire, c.1777.

\section{SENTRY-BOX}

In his early electrical studies, Benjamin Franklin devised an experiment involving a "sentry-box" - a small, roofed structure with a large metal rod protruding from the top. Franklin hypothesized the rod would attract lightning under suitable weather conditions and could then be used to draw a spark effectively demonstrating that lightning is a form of electricity.

Franklin planned to undertake the experiment by installing such a device atop the spire of Christ Church in Philadelphia, but the assembly of the spire proceeded so slowly that he abandoned this plan. While the image of Benjamin Franklin flying a kite in a thunderstorm is embedded in American lore, the event was likely as much the product of impatience with the pace of architectural production as it was of scientific ingenuity.

In the months before Franklin flew his kite, Georges Louis Leclerc and Thomas-François D'Alibard, working from Franklin's writings and accompanying sketch, carried out the experiment in France (figure 4). The first demonstration took place in February, 1752, before a crowd of witnesses including Louis XV. D'Alibard wrote to Franklin to inform him of his proof. Franklin was credited with the discovery and installed similar pointed lightning-attracting devices on his house, the (since completed) Pennsylvania State House, and the Pennsylvania Academy.

The device Franklin installed on his own house was not exactly the protective lightning rod of his own description, but was a kind of experimental circuit, part invention, part construction from others' notes. Notably, the rod was discontinous, and had an apparatus consisting of two bells that would ring when an electrical charge was present, passing through the air between them. A contemporary and rival, the Abbé Nollet, in Paris, had used a similar device to transform his house into

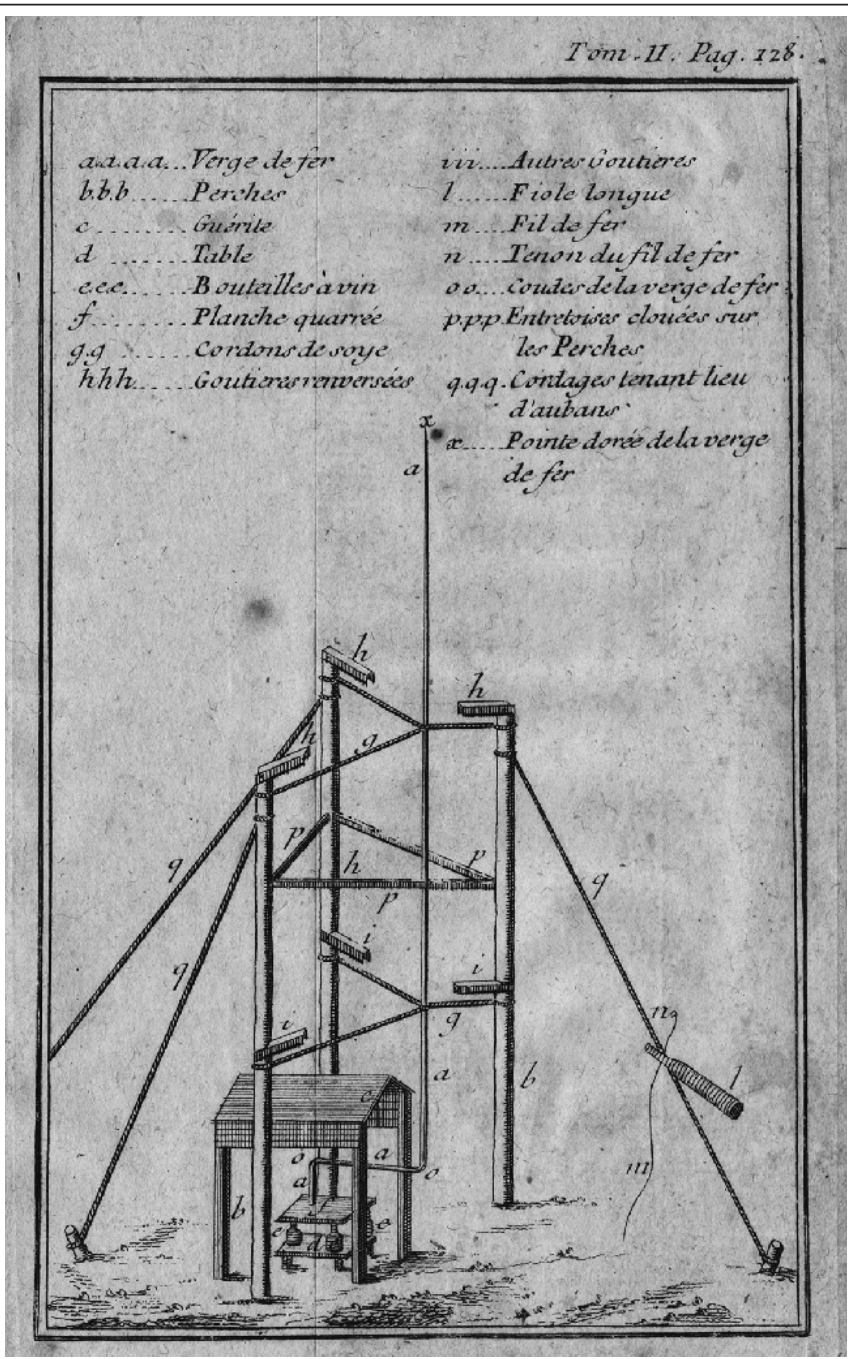

Figure 4: Franklin Sentry Box Experiment, as drawn and undertaken by Thomas-François D'Alibard, 1756. Published in Benjamin Franklin,

Expériences et Observations sur L'Électricité faites a Philadelphie . . . 2nd ed., vol. 2, an extended translation from English by T. F. D'Alibard, Chez Durand, Paris, 1756.

a laboratory for electrical experimentation. These devices begin to hint at an alternative architectural order. Roughly contemporary with Laugier's Essay on Architecture, we could read Nollet's and Franklin's Houses, like the model Thunder Houses on which their devices are modeled, as "Primitive Huts" of a technologically enhanced order.The spires manage lightning's effects on architecture, by moving the path of electricity from an unplanned route through the building to a planned route along a metal line installed on its exterior. Franklin printed a description of his newly engineered device in Poor Richard's Almanac for 1753, in which he encourages the installation of "a small iron rod of such length that, one end being three or four feet in the moist ground, the other may be six or eight feet above the highest part of the building. ${ }^{\prime 3}$ Extending the virtual presence of the building, the rod seeks to systematize lightning's otherwise erratic path 




Figure 5: Empire State Building with Lightning Discharge, General Electric Research Photograph, August 1937

while effectively reversing the traditional threat condition. Increased height offers increased protection.

\section{FARRADAY CAGE}

Studies on the relationship between height and lightning protection paralleled the city's vertical expansion. In 1931, the New York Times science editor declared the Empire State Building "the tallest, most elaborate, and most successful lightning rod ever erected." 4 The steel frame embedded the lightning rod into the very structure of the building. Electricity spreads across the body of the frame, which acts as a Faraday cage rendered at an architectural scale: "Its enormous steel frame protects not only itself but also all the buildings near by." ${ }^{5}$ However, the tower's image as a passive protector appeared to be challenged by casual observation: "Time and time again it has been struck. In fact, hardly a thunderstorm sweeps over lower Manhattan Island that does not single it out to hurl a bolt at its towering mooring mast." 6

Interested in the apparent increase in electrical activity over New York, General Electric rented office space with direct views of the spire and assigned a team of researchers to begin a decade of systematic observation of the tower's lightning-related performance (concluding that the building was actively shaping the electrical field around it) (figure 5).

The line between mythological and actual operation remained ambiguous, even as proven standards emerged to stabilize a relationship between repetition and zone coverage. Visual and/or operational redundancies became the general practice: "There is always, in the event of a theatre being struck by lightning during a performance, the danger of a serious panic. It, therefore, seems proper and wise to provide theatre buildings with the protection which a well-constructed system of lightning-rods affords. The Frankfort-on-Main Opera House is protected by thirteen lightning rod. " Following the establishment of proven performance for an emergency device, redundancy is assumed to further enhance overall safety effects. Against architecture's literal firmness, emergency devices collectively operate to re-code architectural space, collapsing interiority and reshaping enclosure. Culminating in their current ubiquity, the integration of these devices into the spatial and psychological landscape of the city is the story of the Encyclopedia.

\section{ENDNOTES}

1. Basil F. J. Schonland, The Flight of Thunderbolts, (Oxford: Clarendon Press, 1950): 9.

2. Ciara Murphy, "Shocks and Sparks: Participatory Electrical Performances in the Enlightenment Period," in Theatre, Performance and Analogue Technology: Historical Interfaces and Intermedialities, ed. Kara Reilly, Palgrave Studies in Performance and Technology, (New York: Palgrave McMillan, 2013):

3. Benjamin Franklin "How to Secure Houses, \&c from Lightning," from Poor Richard's Almanac, reproduced in Benjamin Franklin's Experiments, ed. I. Bernard Cohen (Cambridge: Harvard University Press, 1941): 453.

4. Waldemar Kaempffert, "Empire State Building Proves an Efficient Conductor -- The Biggest Spectroscope," New York Times, Sunday Section: Special Features Science, July 9, 1933: XX4.

5. Ibid.

6. Ibid.

7. Wm. Paul Gerhard, "The Essential Conditions of Safety in Theatres 1-II," in The American Architect and Building News, 45, 967 (July 7, 1894): 50. 